\title{
Desempenho da cultura do feijão após diferentes formas de uso do solo no inverno
}

\author{
Performance of common bean cultivated after different soil use during the winter
}

\author{
Alvadi Antonio Balbinot Junior ${ }^{I}$ Anibal de Moraes ${ }^{I I}$ Milton da Veiga ${ }^{I I I}$ Adelino PelissariI \\ Jeferson Dieckow ${ }^{\mathrm{IV}}$ Paulo César de Faccio Carvalhov
}

\section{RESUMO}

O uso e manejo do solo durante o inverno pode alterar as características físicas do solo, a cobertura remanescente e o desempenho da cultura semeada em sucessão. O objetivo deste trabalho foi avaliar o efeito de formas de uso do solo no inverno sobre essas variáveis, semeando-se a cultura do feijão em sucessão, manejada em plantio direto. Na safra 2007/08, foram conduzidos três experimentos na região do Planalto Norte Catarinense, onde foram avaliadas cinco formas de uso do solo durante o inverno: 1) consórcio de aveia preta + azevém + ervilhaca + trevo vesiculoso manejado sem pastejo e sem adubação nitrogenada (consórcio cobertura); 2) o mesmo consórcio, com pastejo e com $100 \mathrm{~kg} \mathrm{ha}^{-1}$ de $\mathrm{N}$ em cobertura (pastagem com $N$ ); 3) o mesmo consórcio, com pastejo e sem adubação nitrogenada (pastagem sem $N$ ); 4) nabo forrageiro, sem pastejo e sem adubação nitrogenada (nabo forrageiro); e 5) pousio, sem pastejo e sem adubação nitrogenada (pousio). O consórcio cobertura proporciona maior quantidade de palha para o cultivo de feijão em sucessão, mas as formas de uso do solo no inverno estudadas não afetam expressivamente a densidade e a macroporosidade do solo. $O$ uso do solo no inverno com pastagem anual em sistema integração lavoura-pecuária, coberturas de solo e pousio não afeta o desempenho da cultura do feijão semeada em sucessão, manejada em plantio direto.

Palavras-chave: integração lavoura-pecuária, plantio direto, plantas de cobertura, compactação, Phaseolus vulgaris $L$.

\section{ABSTRACT}

Soil use and management during the winter can affect soil physical properties, reminiscent straw and performance of the crop cultivated in succession. The objective of this study was to evaluate the effect of winter soil use on these variables, cultivating black bean under no tillage system in the summer. Three experiments were carried out in the North Plateau of Santa Catarina State, Brazil, during 2007/08 crop season, with five strategies of soil use during the winter: 1) multicropping with black oat + ryegrass + commom vetch + arrow leaf clover without grazing and nitrogen fertilization (multicropping cover); 2) the same multicropping, with grazing and $100 \mathrm{~kg} \mathrm{ha}^{-1}$ of nitrogen fertilization (pasture with $N$ ); 3 ) the same multicropping, with grazing and without nitrogen fertilization (pasture without N); 4) oil seed radish, without grazing and nitrogen fertilization (oil seed radish); and 5) natural vegetation, without grazing and nitrogen fertilization (fallow). Highest straw dry mass is verified in multicropping cover, but the strategies of winter soil use do not affect significantly the soil bulk density and macroporosity. The soil use with winter annual pasture in crop-livestock system, cover crops and fallow does not affect the black bean performance in succession, under no tillage system.

Key words: crop-livestock, no tillage, cover crops, compaction, Phaseolus vulgaris $L$.

\section{INTRODUÇÃO}

Na região Sul do Brasil, as culturas de soja, milho, arroz e feijão são importantes alternativas de uso de áreas agrícolas durante o período estival. Além dessas culturas graníferas, outras espécies, como o

IEmpresa de Pesquisa Agropecuária e Extensão Rural de Santa Catarina (Epagri), Estação Experimental de Canoinhas, BR 280, km 219,5, CP 216, 89460-000, Canoinhas, SC, Brasil. E-mail: balbinot@epagri.sc.gov.br. Autor para correspondência.

IIDepartamento de Fitotecnia e Fitossanitarismo, Universidade Federal do Paraná (UFPR), Curitiba, PR, Brasil.

IIIEpagri, Estação Experimental de Campos Novos, Campos Novos, SC, Brasil.

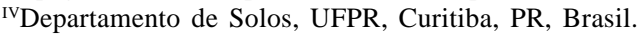

vDepartamento de Plantas Forrageiras e Agrometeorologia, Universidade Federal do Rio Grande do Sul (UFRGS), Porto Alegre, RS, Brasil. 
fumo, a batata e o tomate, também são cultivadas nesse período, ocupando expressivas áreas. Contudo, nos meses de maio a setembro, há carência de alternativas economicamente viáveis de uso do solo, sobretudo em pequenas propriedades rurais. Essa situação estimula o pousio no inverno, o que pode se refletir em menor incorporação de carbono orgânico no sistema, gerando erosão e degradação física, química e biológica do solo ao longo dos anos, especialmente em situações de baixa cobertura do solo pela vegetação espontânea.

As culturas de cobertura do solo de inverno podem melhorar a qualidade do solo (GIACOMINI et al., 2003). Além disso, a manutenção de elevada quantidade de palha sobre o solo, por meio do cultivo dessas coberturas, é fundamental para a sustentabilidade do sistema plantio direto (CERETTA et al., 2002). A presença de palha sobre o solo reduz a infestação por plantas daninhas (BALBINOT JR. et al., 2008) e a erosão hídrica. Todavia, o uso de culturas de cobertura do solo no inverno não traz benefícios econômicos imediatos, mas se constitui num investimento cujo retorno ocorre nas culturas subsequentes.

Uma alternativa viável e eficiente para produzir elevada quantidade de massa pelas culturas de cobertura de solo é o consórcio entre espécies (BALBINOT JR. et al., 2008). O uso do solo no inverno com o cultivo de pastagens em sistema integração lavoura-pecuária pode proporcionar benefícios biológicos e econômicos a curto prazo (TRACY \& ZHANG, 2008). Na região Sul do Brasil, há várias espécies de inverno que podem produzir forragem de elevada qualidade, como aveia preta (Avena strigosa Schreb.), aveia branca (Avena sativa L.), azevém (Lolium multiflorum Lam.) e ervilhacas (Vicia sp.). No entanto, a integração lavoura-pecuária requer manejo adequado, já que o uso do solo no inverno com pastagens pode ocasionar compactação do solo devido ao pisoteio e à falta de palha para o sistema plantio direto (NICOLOSO et al., 2006). Por outro lado, entre 65 e $99 \%$ dos nutrientes absorvidos pelas plantas forrageiras retornam ao solo na forma de resíduos vegetais e excreta animal (KEMP et al., 1999), constituindo-se em uma forma eficiente de ciclagem de nutrientes.

Práticas de manejo que favoreçam o crescimento de raízes e a produção de massa em pastagens podem reduzir os efeitos mecânicos do pisoteio. Nesse sentido, a adubação da pastagem, principalmente com nitrogênio, pode ser uma estratégia para aumentar a produção de forragem e reduzir a compactação superficial ocasionada pelo pisoteio, uma vez que a parte aérea da forragem atenua a pressão aplicada na superfície (BRAIDA et al., 2006), e o crescimento de raízes pode promover descompactação biológica do solo (ABREU et al., 2004).

O objetivo deste trabalho foi avaliar o efeito de formas de uso do solo no inverno sobre a quantidade de palha remanescente, a densidade e a macroporosidade do solo e o desempenho da cultura do feijão semeada em sucessão, em plantio direto.

\section{MATERIAL E MÉTODOS}

Na safra 2007/08, foram conduzidos experimentos em três locais, na região do Planalto Norte de Santa Catarina. Um no município de Canoinhas (local 1: longitude $50^{\circ} 28^{\prime}$ oeste; latitude $26^{\circ} 07^{\prime}$ sul e altitude de 780m) e dois no município de Major Vieira (local 2: longitude $50^{\circ} 18^{\prime}$ ' oeste; latitude $26^{\circ} 27^{\prime}$ ' sul e altitude de $791 \mathrm{~m}$ e local 3: longitude $50^{\circ} 24^{\prime}$ oeste; latitude $26^{\circ} 29^{\prime}$ sul e altitude de $822 \mathrm{~m})$. O clima da região é úmido com verões amenos, do tipo Cfb, segundo a classificação de Köppen. O solo dos locais foi classificado como Cambissolo Háplico (EMBRAPA, 1998). Algumas características do solo, no momento da implantação dos experimentos em cada local de estudo, são apresentadas na tabela 1 .

Tabela 1 - Características de solo na camada de 0 a $0,10 \mathrm{~m}$, no momento da implantação dos experimentos, nos três locais de estudo (maio de 2006). Epagri/Canoinhas, SC, 2006

\begin{tabular}{|c|c|c|c|}
\hline \multirow{2}{*}{ Características } & \multicolumn{3}{|c|}{ 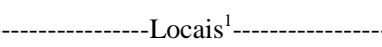 } \\
\hline & 1 & 2 & 3 \\
\hline Argila (\%) & 54,6 & 52,5 & 49,9 \\
\hline Silte (\%) & 40,8 & 39,8 & 44,2 \\
\hline Areia (\%) & 4,6 & 7,7 & 5,9 \\
\hline M.O. (\%) & 5,1 & 5,2 & 6,1 \\
\hline $\mathrm{pH}$ água $1: 1$ & 5,9 & 5,6 & 5,2 \\
\hline $\mathrm{pH}_{\mathrm{SMP}}$ & 6,0 & 5,6 & 5,3 \\
\hline $\mathrm{P}\left(\mathrm{mg} \mathrm{dm}^{-3}\right)$ & 4,5 & 8,0 & 11,4 \\
\hline $\mathrm{K}\left(\mathrm{mg} \mathrm{dm}^{-3}\right)$ & 67,7 & 136,6 & 124,8 \\
\hline $\mathrm{Al}\left(\mathrm{cmol}_{\mathrm{C}} \mathrm{dm}^{-3}\right)$ & 0,08 & 0,09 & 0,7 \\
\hline $\mathrm{Ca}\left(\mathrm{cmol}_{\mathrm{C}} \mathrm{dm}^{-3}\right)$ & 7,8 & 11,1 & 8,7 \\
\hline $\operatorname{Mg}\left(\mathrm{cmol}_{\mathrm{c}} \mathrm{dm}^{-3}\right)$ & 5,0 & 6,1 & 4,9 \\
\hline CTC $\left(\mathrm{cmol}_{\mathrm{C}} \mathrm{dm}^{-3}\right)$ & 17,7 & 25,2 & 24,2 \\
\hline V (\%) & 71,8 & 70,2 & 57,7 \\
\hline $\mathrm{Fe}\left(\mathrm{mg} \mathrm{dm}^{-3}\right)$ & 0,42 & 0,40 & 0,43 \\
\hline $\mathrm{Zn}\left(\mathrm{mg} \mathrm{dm}^{-3}\right)$ & 2,36 & 0,96 & 1,12 \\
\hline $\operatorname{Mn}\left(\mathrm{mg} \mathrm{dm}^{-3}\right)$ & 2,04 & 2,48 & 4,60 \\
\hline $\mathrm{B}\left(\mathrm{mg} \mathrm{dm} \mathrm{m}^{-3}\right)$ & 0,09 & 0,10 & 0,09 \\
\hline $\mathrm{Cu}\left(\mathrm{mg} \mathrm{dm}^{-3}\right)$ & 0,72 & 0,44 & 0,52 \\
\hline
\end{tabular}

${ }^{1}$ Local 1: Canoinhas, SC; Locais 2 e 3: Major Vieira, SC. 
Nos três locais, o delineamento experimental utilizado foi o de blocos completos casualizados, com três repetições. Cada parcela possuía área total de $64 \mathrm{~m}^{2}$ (8 x 8m). Antes da instalação dos experimentos, as áreas vinham sendo manejadas em sistema integração lavoura-pecuária, com uso de pastagens anuais de inverno formadas com aveia preta e/ou azevém. Na safra 2005/06, havia sido cultivada soja (Glycine max L.) no local 1, milheto (Pennisetum americanum (L.) Leeke) havia sido cultivado no local 2 e milho (Zea mays L.) para silagem de planta inteira havia sido cultivado no local 3.

Em maio de 2006, os experimentos foram implantados nos três locais, tendo como tratamentos cinco formas de uso do solo no inverno: 1) consórcio de aveia preta + azevém + ervilhaca (Vicia villosa Roth.) + trevo vesiculoso (Trifolium vesiculosum Savi.) manejado sem pastejo e sem adubação nitrogenada (consórcio cobertura); 2) o mesmo consórcio, com pastejo e com $100 \mathrm{~kg} \mathrm{ha}^{-1}$ de $\mathrm{N}$ em cobertura (pastagem com N); 3) o mesmo consórcio, com pastejo e sem adubação nitrogenada (pastagem sem N); 4) nabo forrageiro (Raphanus sativus L.), sem pastejo e sem adubação nitrogenada (nabo forrageiro); e 5) pousio, sem pastejo e sem adubação nitrogenada (pousio). Na safra 2006/07, foi cultivado milho nos três locais. Em maio de 2007, foram implantados os mesmos tratamentos de inverno, e em sucessão foi semeada a cultura do feijão, a qual foi avaliada para fins deste estudo.

As culturas de inverno foram implantadas no mês de maio de 2007, utilizando-se as seguintes quantidades de sementes: consórcio ( $40 \mathrm{~kg} \mathrm{ha}^{-1}$ de aveia preta $+30 \mathrm{~kg} \mathrm{ha}^{-1}$ de azevém $+30 \mathrm{~kg} \mathrm{ha}^{-1}$ de ervilhaca + $8 \mathrm{~kg} \mathrm{ha}^{-1}$ de trevo vesiculoso); e nabo forrageiro (20kg $\left.\mathrm{ha}^{-1}\right)$. As sementes de trevo vesiculoso foram semeadas a lanço após serem escarificadas mecanicamente, inoculadas com Rhizobium leguminosarum bv. trifolii e peletizadas. Em seguida, as demais espécies foram semeadas em espaçamento entre fileiras de $0,17 \mathrm{~m}$ e profundidade de aproximadamente $0,04 \mathrm{~m}$. Quando a aveia preta apresentava em média dois afilhos, realizouse adubação nitrogenada no tratamento pastagem com $\mathrm{N}$.

Para realizar o pastejo nos tratamentos 2 e 3 , utilizaram-se duas vacas em lactação por parcela, agrupadas de modo que as unidades experimentais recebessem massa animal similar. As vacas utilizadas no local 1 eram da raça Jersey (massa de 400 a $450 \mathrm{~kg}$ cada), enquanto nos locais 2 e 3 as vacas eram da raça Holandesa (massa de 500 a 650kg cada). O indicador utilizado para determinar os momentos de entrada e de saída dos animais foi a altura da pastagem, tendo-se estabelecido a altura média de 0,25 a 0,30m para a entrada dos animais nas parcelas e de $0,1 \mathrm{~m}$ para a saída. As parcelas com pastejo foram separadas das demais por cerca eletrificada.

Durante o ciclo de desenvolvimento da pastagem, foram promovidos quatro pastejos: o primeiro ocorreu aproximadamente 90 dias após a semeadura, com tempo de duração de aproximadamente uma hora; o segundo, aos 27, 28 e 24 dias após o primeiro pastejo, respectivamente nos locais 1 , 2 e 3 , com tempo de duração de quatro a cinco horas; o terceiro, aos 17, 17 e 21 dias após o segundo pastejo, com tempo de duração de cinco a seis horas; e o quarto, aos 29, 30 e 30 dias após o terceiro pastejo, respectivamente nos locais 1,2 e 3 , com tempo de duração de cinco a seis horas. No dia 10/11/2007, realizou-se a dessecação das plantas remanescentes em todos os tratamentos, utilizando-se glyphosate (1.440 $\mathrm{g} \mathrm{ha}^{-1}$ de i.a.) e óleo mineral (1,5L ha-1), aplicados com pulverizador costal.

A cultura do feijão foi semeada nos dias 26/ 11/2007 (local 1) e 21/11/2007 (locais 2 e 3). O experimento foi implantado com semeadora equipada com facão sulcador, com profundidade de ação de aproximadamente $0,1 \mathrm{~m}$. A adubação de base e de cobertura foi realizada de acordo com as recomendações técnicas (CQFS RS/SC, 2004). Utilizouse a cultivar de feijão preto 'IPR Uirapuru', semeada em espaçamento de $0,45 \mathrm{~m}$ entre fileiras e 220 mil plantas $\mathrm{ha}^{-1}$. O controle de plantas daninhas foi realizado com os herbicidas fluazifop-p ( $200 \mathrm{~g} \mathrm{ha}^{-1}$ de i.a.) + fomesafen (250g ha-1 de i.a.). Logo após o florescimento, aplicaram-se os fungicidas clorotalonil (700g ha-1 de i.a.) e tiofanato-metílico ( $280 \mathrm{~g} \mathrm{ha}^{-1}$ de i.a.).

Avaliou-se o consumo de pastagem pelos animais nos tratamentos 2 e 3, por meio de coleta de duas amostras de pastagem presente em $0,25 \mathrm{~m}^{2}$ antes da entrada dos animais e duas após a saída destes. As plantas foram cortadas rente ao solo e secas em estufa a $60^{\circ} \mathrm{C}$, até atingirem massa constante, quando foram pesadas. A diferença de massa entre a entrada e a saída dos animais constituiu a massa consumida pelos animais durante o pastejo. No momento da dessecação, na pré-semeadura do feijão, avaliou-se a quantidade de palha remanescente dos tratamentos de inverno, por meio de coleta em área de $1 \mathrm{~m}^{2}$ por parcela. Por ocasião da semeadura do feijão, foram coletadas, em anéis volumétricos, duas amostras indeformadas de solo por parcela, sendo uma na camada de 0,02 a $0,07 \mathrm{~m}$ e outra na camada de 0,10 a $0,15 \mathrm{~m}$, nas quais foram determinadas a densidade do solo e a macroporosidade (EMBRAPA, 1997). Na análise estatística das variáveis de física do solo, as camadas avaliadas foram consideradas subparcelas. Quando as plantas de feijão 
estavam em maturação de colheita, foram coletadas 10 plantas ao acaso na área útil de cada parcela, nas quais se determinaram os componentes de rendimento da cultura (número de vagens por planta, número de grãos por vagem e massa de mil grãos). Além disso, as plantas presentes na área útil $\left(5,4 \mathrm{~m}^{2}\right)$ foram colhidas e trilhadas, e foi determinada a massa de grãos, a qual foi corrigida para $13 \%$ de umidade para estimar a produtividade de grãos.

Realizou-se análise estatística por local, individualmente, sendo os dados submetidos à análise de variância e ao teste $\mathrm{F}$, e as médias comparadas pelo teste Tukey, a 5\% de probabilidade de erro.

\section{RESULTADOS E DISCUSSÃO}

Nos três locais, o tratamento pastagem com $\mathrm{N}$ proporcionou maior consumo de forragem em relação à pastagem sem $\mathrm{N}$ (Tabela 2). Isso ocorreu porque o aumento da disponibilidade de $\mathrm{N}$ no solo proporciona incremento na produção de pastagens, especialmente em espécies da família Poacea (LESAMA \& MOOJEN, 1999; SOARES \& RESTLE, 2002).
Maior quantidade de palha remanescente para implantação da cultura do feijão em plantio direto foi observada no tratamento consórcio cobertura, nos três locais (Tabela 2). A cobertura com nabo forrageiro proporcionou baixa quantidade de palha, principalmente no local 1, como observado por BALBINOT JR. et al. (2008), em pesquisa realizada no Planalto Norte Catarinense. O tratamento pousio também disponibilizou baixa quantidade de palha, pois houve germinação esparsa de plantas de azevém, oriundas do banco de sementes do solo. Além disso, nos tratamentos com pastagens, houve baixa disponibilidade de palha em decorrência do consumo de massa vegetal pelos animais. A baixa produção de palha pode se refletir diretamente na sustentabilidade do sistema plantio direto, uma vez que a manutenção de elevada quantidade de palha sobre o solo é um alicerce do referido sistema (CERETTA et al., 2002). A baixa disponibilidade de palha pode resultar em aumento da infestação por plantas daninhas durante o ciclo da cultura estival, aumentando os custos com herbicidas e/ou reduzindo a sua produtividade (BALBINOT JR. et al., 2008), além de reduzir a retenção de água no solo e aumentar a erosão hídrica.

Tabela 2 - Consumo de massa seca de pastagem em cada pastejo e palha remanescente no momento da dessecação, em diferentes formas de uso do solo no inverno, nos três locais de estudo, Epagri/Canoinhas, SC, 2007/08.

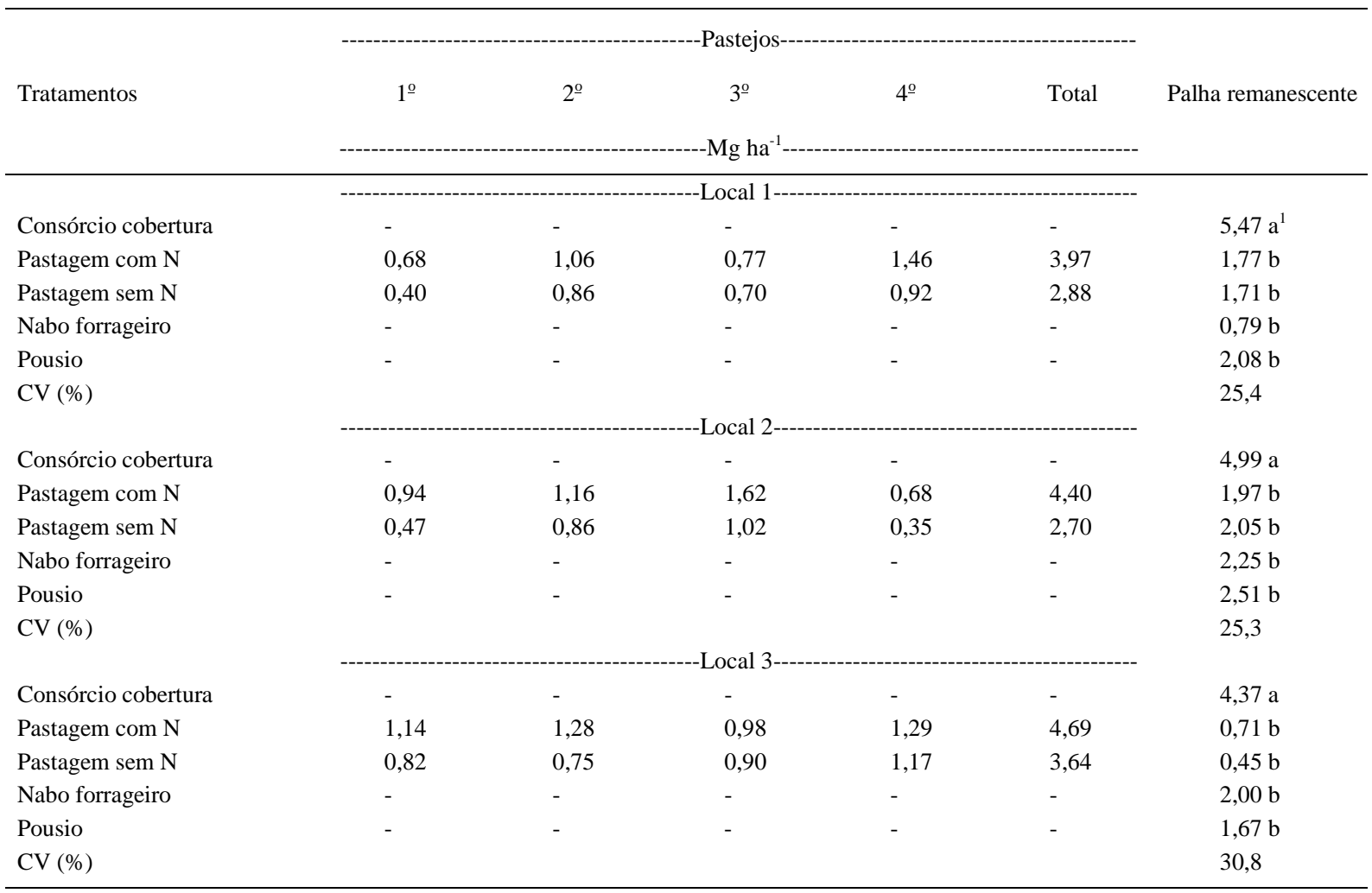

${ }^{1}$ Médias não seguidas de mesma letra na coluna, para cada local, diferem entre si pelo teste de Tukey, a 5\% de probabilidade. 
Em geral, não houve variação entre tratamentos quanto à densidade do solo e macroporosidade, avaliadas no momento de implantação da cultura do feijão em sucessão às formas de uso do solo no inverno (Tabela 3). Também não houve efeito das camadas de solo e da interação entre camadas e tratamentos para essas duas variáveis. No local 1, a densidade do solo nos tratamentos com pastagem foi superior à densidade observada no pousio, na média das duas camadas de solo avaliadas, porém não diferindo dos tratamentos consórcio cobertura e nabo forrageiro. Nos três locais, a densidade do solo ficou abaixo de valores considerados críticos para o crescimento de raízes, considerando os teores de argila dos solos (Tabela 1) (REICHERT et al., 2007).

A ausência de compactação significativa decorrente do pisoteio animal, observada nos três locais, pode ser atribuída, principalmente, ao manejo adequado da pastagem. A manutenção da pastagem em altura que permita elevada interceptação de radiação solar é fator importante para que o sistema integração lavoura-pecuária tenha êxito. Essa condição resulta em grande área fotossinteticamente ativa e,

Tabela 3 - Densidade e macroporosidade do solo em diferentes formas de uso do solo no inverno, nos três locais de estudo. Média de duas camadas de solo $(0,02$ a $0,07 \mathrm{~m}$ e 0,10 a 0,15m), Epagri/Canoinhas, SC, 2007/08.

\begin{tabular}{lcc}
\hline Tratamentos & $\begin{array}{c}\text { Densidade } \\
\left(\mathrm{Mg} \mathrm{m}^{-3}\right)\end{array}$ & $\begin{array}{c}\text { Macroporosidade } \\
\left(\mathrm{m}^{3} \mathrm{~m}^{-3}\right)\end{array}$ \\
\hline Consórcio cobertura & $1,19 \mathrm{ab}^{1}$ & $0,136 \mathrm{a}$ \\
Pastagem com N & $1,27 \mathrm{a}$ & $0,142 \mathrm{a}$ \\
Pastagem sem N & $1,25 \mathrm{a}$ & $0,155 \mathrm{a}$ \\
Nabo forrageiro & $1,23 \mathrm{ab}$ & $0,159 \mathrm{a}$ \\
Pousio & $1,16 \mathrm{~b}$ & $0,204 \mathrm{a}$ \\
CV (\%) & 4,5 & 27,3 \\
& ------------------ Local 2----------------- \\
Consórcio cobertura & $1,20 \mathrm{a}$ & $0,122 \mathrm{a}$ \\
Pastagem com N & $1,23 \mathrm{a}$ & $0,125 \mathrm{a}$ \\
Pastagem sem N & $1,21 \mathrm{a}$ & $0,122 \mathrm{a}$ \\
Nabo forrageiro & $1,17 \mathrm{a}$ & $0,136 \mathrm{a}$ \\
Pousio & $1,18 \mathrm{a}$ & $0,132 \mathrm{a}$ \\
CV (\%) & 5,3 & 23,0 \\
& 1,3 & $0,123 \mathrm{a}$ \\
Consórcio cobertura & $1,12 \mathrm{a}$ & $0,133 \mathrm{a}$ \\
Pastagem com N & $1,12 \mathrm{a}$ & $0,112 \mathrm{a}$ \\
Pastagem sem N & $1,14 \mathrm{a}$ & $0,138 \mathrm{a}$ \\
Nabo forrageiro & $1,13 \mathrm{a}$ & 23,2 \\
Pousio & $1,12 \mathrm{a}$ & \\
CV (\%) & & \\
\hline
\end{tabular}

${ }^{1}$ Médias não seguidas de mesma letra na coluna, para cada local, diferem entre si pelo teste de Tukey, a 5\% de probabilidade. consequentemente, em elevado crescimento de folhas e raízes, conferindo ao solo maior capacidade de suporte de carga sem resultar em compactação, bem como maior capacidade de recuperação após aplicação de cargas. O elevado crescimento de raízes é certamente fator importante para reduzir o nível de compactação decorrente de pressões mecânicas exercidas sobre o solo, pois as raízes têm a capacidade de promover a agregação do solo, tanto por efeito mecânico, como pela liberação de exsudatos no solo. Além disso, a parte aérea da pastagem atenua o efeito mecânico do pisoteio sobre o solo, reduzindo a compactação (BRAIDA et al., 2006).

Não houve efeito de tratamentos sobre os componentes de produção do feijão (número de vagens por planta, número de grãos por vagem e massa de mil grãos) e sobre a produtividade de grãos (Tabela 4). Isso confirma que o uso do solo no inverno com pastagem anual bem manejada não causa compactação do solo, nem tampouco prejudica a cultura do feijão semeada em sucessão, em plantio direto, além de gerar renda no inverno por meio da produção de leite e/ou carne. Na literatura há poucos trabalhos demonstrando o efeito de pastagens anuais de inverno sobre a cultura do feijão semeada em sucessão, em plantio direto. No entanto, ASSMANN et al. (2003) verificaram que o pastejo de aveia branca e azevém no inverno não afetou o desempenho do milho semeado em sucessão, em plantio direto. De acordo com NICOLOSO et al. (2006), há redução da produtividade do milho semeado em sucessão à pastagem de inverno somente quando há elevada frequência e pressão de pastejo. Em soja, LUNARDI et al. (2008) verificaram que o pastejo de azevém, em sistema integração lavoura-pecuária, favoreceu a produtividade de grãos em relação à área não pastejada.

Outro aspecto importante é que não houve diferença de componentes de produção e produtividade de grãos de feijão em função da adubação nitrogenada da pastagem de inverno (Tabela 4). Possivelmente isso tenha ocorrido devido à compensação da ausência de adubação nitrogenada pela fixação desse elemento pela ervilhaca e pelo trevo vesiculoso presentes na pastagem, o qual pode ser disponibilizado para a cultura do feijão após a decomposição da massa dessas espécies. Além disso, a cultura do feijão, por ser uma leguminosa, possui a capacidade de fixar $\mathrm{N}$ atmosférico, reduzindo a resposta à adubação nitrogenada. Por outro lado, ASSMANN et al. (2003) constataram, em pastagem de aveia branca e azevém com e sem trevo-branco, efeito residual da adubação nitrogenada da pastagem de inverno sobre a produtividade de milho semeado em sucessão. 
Tabela 4 - Componentes de produção e produtividade de grãos da cultura do feijão em sucessão a diferentes formas de uso do solo no inverno, nos três locais de estudo, Epagri/Canoinhas, SC, 2007/08.

\begin{tabular}{|c|c|c|c|c|}
\hline \multirow{2}{*}{ Tratamentos } & \multirow[b]{2}{*}{ № vagens por planta } & \multirow[b]{2}{*}{ № grãos por vagem } & \multirow[b]{2}{*}{ Massa de mil grãos (g) } & \multirow[b]{2}{*}{ Produtividade (Mg ha $\left.{ }^{-1}\right)$} \\
\hline & & & & \\
\hline Consórcio cobertura & $14,1 \mathrm{a}$ & $6,1 \mathrm{a}$ & $252 \mathrm{a}$ & $3,40 a^{1}$ \\
\hline Pastagem com N & 15,5 a & 5,7 a & $245 \mathrm{a}$ & $3,44 \mathrm{a}$ \\
\hline Pastagem sem N & 11,5 a & 6,1 a & $247 \mathrm{a}$ & 3,48 a \\
\hline Nabo forrageiro & 16,3 a & $6,1 \mathrm{a}$ & 257 a & 3,62 a \\
\hline Pousio & $12,1 \mathrm{a}$ & 6,2 a & 265 a & 3,29 a \\
\hline CV (\%) & 14,6 & 3,3 & 3,7 & 9,1 \\
\hline Consórcio cobertura & 13,6 a & 5,2 a & $203 \mathrm{a}$ & $2,34 \mathrm{a}$ \\
\hline Pastagem com N & 14,8 a & $5,0 \mathrm{a}$ & $205 \mathrm{a}$ & 1,87 a \\
\hline Pastagem sem N & 11,5 a & 5,7 a & $178 \mathrm{a}$ & $1,98 \mathrm{a}$ \\
\hline Nabo forrageiro & $14,8 \mathrm{a}$ & 5,5 a & 209 a & $2,34 \mathrm{a}$ \\
\hline Pousio & 10,5 a & $5,3 \mathrm{a}$ & $190 \mathrm{a}$ & $1,54 \mathrm{a}$ \\
\hline CV (\%) & 16,8 & 8,6 & 5,8 & 25,9 \\
\hline Consórcio cobertura & 13,5 a & 6,3 a & $253 \mathrm{a}$ & 3,12 a \\
\hline Pastagem com N & $12,7 \mathrm{a}$ & 5,9 a & $249 \mathrm{a}$ & 3,11 a \\
\hline Pastagem sem N & $11,3 \mathrm{a}$ & 5,4 a & $250 \mathrm{a}$ & 3,41 a \\
\hline Nabo forrageiro & 14,9 a & 5,7 a & $241 \mathrm{a}$ & $2,95 \mathrm{a}$ \\
\hline Pousio & 9,3 a & 5,3 a & 252 a & 2,98 a \\
\hline CV (\%) & 29,9 & 11,1 & 7,2 & 13,3 \\
\hline
\end{tabular}

${ }^{1}$ Médias não seguidas de mesma letra na coluna, para cada local, diferem entre si pelo teste de Tukey, a 5\% de probabilidade.

\section{CONCLUSÃO}

Pastagem anual de inverno em sistema integração lavoura-pecuária, coberturas de solo de inverno e pousio não afetam a densidade e a macroporosidade do solo, bem como o desempenho da cultura do feijão semeada em sucessão, sob plantio direto.

\section{AGRADECIMENTOS}

Aos produtores rurais Amélio Gudas, Danilo Guedes e Ivo Grein, pelo auxílio na condução dos experimentos.

\section{REFERÊNCIAS}

ABREU, S.L. et al. Escarificação mecânica e biológica para a redução da compactação em Argissolo franco-arenoso sob plantio direto. Revista Brasileira de Ciência do Solo, Viçosa, v.28, n.3, p.519-531, 2004. Disponível em: <http:// www.scielo.br/scielo.php?script $=$ sci_arttext \&pid $=$ S0100 06832004000300013\&lng=pt\&nrm=iso $>$. Acesso em: 23 mai. 2008. doi: 10.1590/S0100-06832004000300013.

ASSMANN, T.S. et al. Rendimento de milho em área de integração lavoura-pecuária sob o sistema plantio direto, em presença e ausência de trevo branco, pastejo e nitrogênio.
Revista Brasileira de Ciência do Solo, Viçosa, v.27, n.4, p.675-683, 2003. Disponível em: <http://www.scielo.br/ s cielo.php? script = sci_art text \& pid = S 0100 06832003000400012\&lng=pt\&nrm=iso $>$. Acesso em: 20 mar. 2008. doi: 10.1590/S0100-06832003000400012.

BALBINOT JR., A.A. et al. Formas de uso do solo no inverno e sua relação com a infestação de plantas daninhas em milho (Zea mays) cultivado em sucessão. Planta Daninha, Viçosa, v.26, n.3, p.569-576, 2008. Disponível em: <http:// www.scielo.br/scielo.php?script $=$ sci_arttext \&pid=S0100 $83582008000300012 \& \operatorname{lng}=p t \& n r m=i s o>$. Acesso em: 18 set. 2008. doi: 10.1590/S0100-83582008000300012.

BRAIDA, J.A. et al. Resíduos vegetais na superfície e carbono orgânico do solo e suas relações com a densidade máxima obtida no ensaio proctor. Revista Brasileira de Ciência do Solo, Viçosa, v.30, n.4, p.605-614, 2006. Disponível em: < http:// www.scielo.br/scielo.php?script $=$ sci_arttext\&pid=S010006832006000400001\&lng=pt\&nrm=iso >. Acesso em: 19 mar. 2008. doi: 10.1590/S0100-06832006000400001.

CERETTA, C.A. et al. Produção e decomposição de plantas invernais de cobertura de solo e milho, sob diferentes manejos da adubação nitrogenada. Ciência Rural, Santa Maria, v.32, n.1, p.49-54, 2002. Disponível em: <http://www.scielo.br/ s ci elo.ph p ? s cript = sci_art text \& pid=S 0103 84782002000100009\&lng=pt\&nrm=iso $>$. Acesso em: 19 mar. 2008. doi: 10.1590/S0103-84782002000100009.

COMISSÃO DE QUÍMICA E FERTILIDADE DO SOLO CQFS RS/SC. Manual de adubação e calagem para os

Ciência Rural, v.39, n.8, nov, 2009. 
Estados do Rio Grande do Sul e de Santa Catarina. 10.ed. Porto Alegre: SBCS/Núcleo Regional Sul, 2004. 400p.

EMBRAPA. Manual de métodos de análise do solo. Rio de Janeiro: Embrapa, 1997. 212p.

EMBRAPA - Centro Nacional de Pesquisa de Solos. Levantamento de reconhecimento de solos do Estado de Santa Catarina. Rio de Janeiro: EMBRAPA, 1998. CD ROM (Boletim de Pesquisa, 6).

GIACOMINI, S.J. et al. Matéria seca, relação C/N e acúmulo de nitrogênio, fósforo e potássio em misturas de plantas de cobertura de solo. Revista Brasileira de Ciência do Solo, Viçosa, v.27, n.2, p.325-334, 2003. Disponível em: <http:// www.scielo.br/scielo.php?script $=$ sci_arttext\&pid=S0100 $06832003000200012 \& \operatorname{lng}=$ pt\&nrm=iso $>$. Acesso em: 25 mai. 2008. doi: 10.1590/S0100-06832003000200012.

KEMP, P.D. et al. Pastures and soil fertility. In: WHITE, J.; HODGSON, J. New Zealand: pastures and crop science. Auckland: Oxford University, 1999. Cap. 4, p.45-58.

LESAMA, M.F.; MOOJEN, E.L. Produção animal em gramíneas de estação fria com fertilização nitrogenada ou associadas com leguminosa, com ou sem fertilização nitrogenada. Ciência Rural, Santa Maria, v.29, n.1, p.123-128, 1999. Disponível em: <http:/ /www.scielo.br/scielo.php?script=sci_arttext\&pid=S010384781999000100022\&lng=pt\&nrm=iso >. Acesso em: 30 mai. 2008. doi: 10.1590/S0103-84781999000100022.
LUNARDI, R. et al. Rendimento de soja em sistema de integração lavoura-pecuária: efeito de métodos e intensidade de pastejo. Ciência Rural, Santa Maria, v.38, n.3, p.795-801, 2008. Disponível em: $<$ http://www.scielo.br/scielo.php?script=sci_arttext\&pid=S010384782008000300032\&lng=pt\&nrm=iso>. Acesso em: 10 ago. 2008. doi: 10.1590/S0103-84782008000300032.

NICOLOSO, R.S. et al. Manejo das pastagens de inverno e potencial produtivo de sistemas de integração lavoura-pecuária no Estado do Rio Grande do Sul. Ciência Rural, Santa Maria, v.36, n.6, p.1799-1805, 2006. Disponível em: <http:// www.scielo.br/scielo.php?script $=$ sci_arttext $\&$ pid $=$ S0103$84782006000600020 \& \operatorname{lng}=p t \& n r m=i s o>$. Acesso em: 20 mai. 2008. doi: 10.1590/S0103-84782006000600020.

REICHERT, J.M. et al. Compactação do solo em sistemas agropecuários e florestais: identificação, efeitos, limites críticos e mitigação. Tópicos em Ciência do Solo, Viçosa, v.5, p.49134, 2007.

SOARES, A.B.; RESTLE, J. Produção animal e qualidade de forragem de pastagem de triticale e azevém submetida a doses de adubação nitrogenada. Revista Brasileira de Zootecnia, Viçosa, v.31, n.2, p.908-917, 2002. Disponível em: <http:// www.scielo.br/scielo.php? script=sci_arttext\&pid=S1516$35982002000400014 \& \operatorname{lng}=p t \& n r m=i s o>$. Acesso em: $10 \mathrm{fev}$. 2008. doi: 10.1590/S1516-35982002000400014.

TRACY, B.F.; ZHANG, Y. Soil compaction, corn yield response, and soil nutrient pool dynamics within an integrated croplivestock system in Illinois. Crop Science, Madison, v.48, n.3, p.1211-1218, 2008. 